JKEP

Vol 5, No 1, Mei 2020

ISSN: 2354-6042 (Print)

ISSN : 2354-6050 (Online)

\title{
Edukasi Kesehatan Meningkatkan Pengetahuan Dan Keterampilan Keluarga Dalam Pencegahan Jatuh Pada Lansia
}

\author{
Aan Nurhasanah, Nurdahlia \\ Jurusan Keperawatan. Poltekkes Kemenkes jakarta 3 \\ Email : annur1408@yahoo.co.id
}

\author{
Artikel history \\ Dikirim, May $2^{\text {nd }}, 2020$ \\ Ditinjau, May $9^{\text {th }}, 2020$ \\ Diterima, May $10^{\text {th }}, 2020$
}

\begin{abstract}
Health Education improves family knowledge and performance in preventing the risk of falling from Lania. The population is all the elderly in crocodile holes that have fallen. The number of samples is 50 people. Sampling with proportional sampling. Collected using a questionnaire and analyzed by univatriate, bivatriate (dependent t test), and multivatriate with manova analysis. The results of the study showed significant differences before and given health education on knowledge $(p=0.001)$ with a difference in the average value $=0.9183$, and a family skills score with a value of $p=$ 0.035 ) with a difference in the average value $=1,100$. gender is assessed against the level of knowledge with a value of $P$ value $=0,000$ and the status of the job depends on the skill value of the $p$ value of 0.001. then it can help the success of education can improve aspects of family knowledge and skills in making failures in the elderly. Provided that proper education is given to families as a form of self-care and to implement appropriate environmental management to prevent the risk of falls.
\end{abstract}

Keywords: Health education, Family, Skills, Elderly. Knowledge. Fall prevention

\begin{abstract}
ABSTRAK
Edukasi Kesehatan meningkatkan pengetahuan dan keterampilan keluarga dalam pencegahan risiko jatuh pada Lansia. Penelitian ini bertujuan untuk mengetahui pengaruh edukasi pada keluarga dalam pencegahan risiko jatuh pada lansia sebelum dan sesudah diberikan intervensi berupa penyuluhan kesehatan. Disain penelitian ini Quasi eksperimenpre-post test without control group.Populasinya adalah seluruh lansia dikelurahan lubang buaya yang pernah jatuh. Jumlah sampel 50 orang. Pengambilan sampel secara propotional sampling. Dikumpulkan dengan menggunakan kuestioner dan dianalisis secara univatriate, bivatriate (uji t test dependen), dan multivatriate dengan analisis manova. HasilPenelitian terdapat perbedaan signifikan sebelum dan sesudah diberikan edukasi kesehatan pada pengetahuan $(\mathrm{p}=0,001)$ dengan selisihnilai rata-rata $=0.9183$, dan skor keterampilan keluarga dengan nilai $\mathrm{p}=0,035)$ dengan
\end{abstract}


selisihnilai rata-rata $=1.100$.jenis kelamin berpengaruh terhadap tingkat pengetahuan dengan nilai $\mathrm{P}$ value $=0.000$ dan status pekerjaan berpengaruh terhadap keterampilan nilai $\mathrm{p}$ value 0.001 . maka dapat disimpulkan pemberian edukasi dapat mempengaruhi pada aspek pengetahuan dan keterampilan keluarga dalam melakukan pencegahan jatuh pada lansia. Disarankan agar diberikanedukasi yang tepat pada keluarga sebagai bentuk intervensi keperawatan mandiri dan melakukan pengelolaan lingkungan yang tepat dalam rangka upaya pencegahan risiko jatuh

Kata kunci: Edukasi Kesehatan, Keluarga, Keterampilan, Lansia. Pengetahuan. Pencegahan jatuh

\section{PENDAHULUAN}

Lansia adalah seseorang yang telah mencapai usia lebih dari 60 tahun (Maryam, 2008). Proses menua merupakan proses yang terjadi secara alamiah dimulai sejak lahir yang dialami oleh semua mahluk yang hidup di duni (nugroho, 2000). Secara global penduduk dengan rata-rata usia 60 tahun yang biasa dibut lansia di dunia diperkirakan mencapai 500 jiwa yang diperkirakan pada tahun 2025 akan mencapai 1.2 milyar jiwa ( bandiyah.2009 ).Badan Pusat Statistiuk (BPS) memperkirakan jumlah lansia pada tahun 2020 akan mencapai 29.120000 jiwa dengan umur harapan hidup menjadi 70-75 tahun. Peningkatan jumlah lansia dipengaruhi oleh majunya peningkatan pelayanan kesehatan, perbaikan gizi dan sanitasi,menurunnya angka kematian bayi, serta meningkatnya pengawasan terhadap penyakit infeksi
Nugroho.2008).Peningkatan jumlah lansia dari tahun ke tahun berkaitan dengan keberhasilan pembangunan di berbagai bidang, terutama adanya perbaikan kualitas kesehatan dan kondisi sosial masyarakat, menimbulkan tantangan yang harus dihadapi diantaranya peningkatan angka beban tanggungan penduduk usia produktif yaitu keluarga terhadap kelompok usia tidak produktif seperti lansia. Hal ini dikarenakan peningkatan kuantitas lansia tidak diimbangi dengan kualitas lansia yang secara fisiologis terjadi penurunan dalam berbagai aspek baik fisik, mental sosial dan spiritualnya.

Secara umum menjadi tua atau menua (Ageing process), ditandai oleh kemunduran . Pada aspek Fisik banyak terjadi penurunan yang salah satunya faktor ketidak seimbangan yang menimbulkan risioko jatuh. Jatuh 
merupakan salah satu penyebab dari kematian yang bisa terjadi pada lansia juga penyebab masalah fisik yang sering terjadi pada lasia. Hal ini disebabkan karena dengan bertambahnya usia terjadi perubahanperubahan baik yang bersifat fisiologis dan mental. Akibat dari adanya perubahan fungsi dalam organ tubuh menyebabkan individu mengalami masalah dalam pememenuhan kebutuhan aktivitas sehari-hari. Akan tetapi bukan berarti para lansia ini hidup tergantung. Banyak Lansia yang masih bisa mandiri. Lansia perlu tetap hidup eksis dalam menjalani kehidupannya, oleh karena itu perlu ada dukungan dari lingkungan keluarganya, bisa berupa verbal maupun non verbal yang bersifat nyata berupa kehadiran sehingga berpengaruh positif pada dirinya.

Jatuh merupakan hasil dari campuran interaktif dan kompleks dari factor biologis, perilaku dan lingkungan dan diantaranya dapat dicegah (Kamel, Abdulmajeed\& Ismail, 2013). Duapuluh hingga tiga puluh persen dari lansia yang memiliki deraja kecacatan tinggi terkait jatuh akan mengalami kehilangan kebebasan akan ADL (aktivitas hidup sehari-hari), penurunan kualitas hidup dan yang paling memprihatinkan adalah kematian (Jamebozorgi et al, 2013). Kurang dukungan keluarga pada lansia, Jatuh pada lansia dipengaruhi oleh 2 faktor yaitu faktor intrinsik dan faktor ekstrinsik (Lemier \& Silver, 2008). Faktor intrinsik seperti gender, kelemahan otot, defisit sensorik, penyakit kronis, gangguan kognitif dan usia (Edelberg, 2006). Faktor ekstrinsik seperti narkoba, faktor lingkungan, kebanyakan mengkonsumsi alkohol, ketidak tahuan prinsip keselamatan, penggunaan sepatu yang tidak tepat dan desain rumah (Jamebozorgiet al, 2013). Menurut Riskesdas 2013 Prevalensi jatuh pada lansia dengan karakteristik usia 65 sampai 74 tahun sebesar $67.1 \%$ sedangkan usia di atas 75 tahun sebesar $76.2 \%$.

Usaha pencegahan merupakan langkah awal yang harus dilakukan dengan memberikan edukasi pada keluarga atau orang-orang terdekatnya melalui suatu kegiatan pemberian penyuluhan kesehatan dengan harapan dapat mengindentifikasi factor risiko, penilaian keseimbangan dan gaya berjalan, latihan fleksibilitas gerakan, latihan 
keseimbangan fisik dan koordinasi keseimbangan, dan memperbaiki kondisi lingkungan yang dianggap tidak aman. Untuk melakukan pencegahan agar lansia tidak beresiko untuk jatuh, maka diperlukan pengetahuan dan keterampilan yang perlu dilakukan oleh orang-orang terdekatnya seperti keluarga, sepertianak, cucu, menantu atau anggota keluarga yang lain. Melalui pengetahuan dan keterampilan yang dikuasai dengan baik oleh orang-orang terdekatnya akan meminimalisir angka kejadian jatuh pada lansia karena tercipta lingkungan yang aman bagi lansia.

Hal yang bias dilakukan adalah memodifikasi lingkungan rumah seperti membuat lantai tidak licin, lantai yang rata, tidak ada barang-barang yang berserakan di lantai, pencahayaan yang cukup dan tidak menyilaukan serta mengurangi tangga yang ada di jalur lansia berjalan. Sekitar 24\% lansia jatuh ditangga dan $36 \%$ jatuh terjadi diluar (Kamel, Abdulmajeed \& Ismail, 2013). Keluarga mempunyai peranan penting untuk kelangsungan hidup lansia kearah yang lebih baik, salah satunya adalah mencegah terjadinya jatuh pada lansia. Di sini bias berfungsi sebagai sistem pendukung bagi anggotanya dengan berperan dan siaga untuk memberikan bantuan jika individu membutuhkan pertolongan tanpa menjadikan individu menjadi ketergantungan. Seseorang dapat memerankan sebagai sebuah kolektor dan disseminator (penyebar) informasi tentang yang ada disekelilingnya, pemberian nasehat, petunjuk-petunjuk, saran atau umpan balik. Tentang aktifitas sehari-hari, pola makan sehari-hari dan pengobatan. Sehingga lansia merasakan mendapat perhatian, disenangi, dihargai .Hasil Penelitan Nita Utami (2017) yang berjudul hubungan dukungan keluarga dengan risiko jatuh pada lansia mengungkapkan bahwa dukungan dari keluarga ada hubungan antara dukungan keluarga dengan risiko jatuh. Hal ini diperkuat juga oleh penelitian Setya budi S., (2016) dalam penelitiannya menyatakan terdapat hubungan signifikan antara dukungan keluarga dengan risiko jatuh di Notoyudan RW 24 Pringgo kusuman Yogyakarta. Juga penelitian Budi Alif Kurniawan pada tahun 2014 tentang hubungan pengetahuan dan perilaku keluarga dengan resiko jatuh pada lansia menyatakan terdapat hubungan antara perilaku yang dimiliki oleh keluarga yang didukung dengan factor pendukung seperti lingkungan yang 
baik, social ekonomi keluarga yang baik dan kesehatan lansia yang baik maka akan menghasilkan resiko jatuh rendah dan bahkan tidak beresiko pada lansia.

Peran perawat merupakan seperangkat perilaku yang diharapkan oleh seorang individu yang sesuai dengan status sosialnya, peran yang dijalankan harus sesuai dengan lingkup kewenangan perawat. Peran perawat sangat penting dalam pelaksanaan keselamatan pasien/klien khususnya lansia dari kejadian jatuh melalui pemberian edukasi pada keluarga contohya dengan memperhatikan masalah eliminasi dan bahkan memperhatikan masalah depresi yang di derita pasien (Younce et al, 2011).Salan satu peran Perawat yang berhubungan dengan pencegahan resiko jatuh adalah melakukan pengkajian resiko jatuh seperti pada Pengkajian Morse Fall Score (MFS) atau Humpy-Dumty Fall Scale. Selain itu seorang perawat hendaknya melakukan edukasi kepada pasien yaitu Setelah masalah terhadap resiko jatuh ditemukan perawat perlu melakukan tindakan intervensi pencegahan pasien resiko jatuh berdasarkan standard operasional.

Berdasarkan pemaparan latar belakang diatas peneliti tertarin meneliti bagaimana pengaruh edukasi terhadap pengetahuan dan keterampilan keluarga dalam pencegahan jatuh pada lansia?

\section{METODE PENELITIAN}

Metode penelitian menggunakan penelitian kuantitatif dengan rancangan quasi eksperimen pre - post test without control group Proses pelaksanaan penelitian, peneliti melakukan pre test terlebih dahulu, kemudian pelaksanaan edukasi berupa pendidikan kesehatan tentang pencegahan risiko jatuh, kemudian dilakukan pengukuran sesudah edukasi

Populasi pada penelitian ini adalah seluruh keluarga yang memiliki lansia di wilayah Puskesmas Lubang Buaya, sedangkan sampel pada penelitianini sebanyak 50 Keluarga dengan lansia yang berada di wilayah RW 09 Kelurahan Lubang buaya yang memenuhi kriteria inklusi antara lain keluarga dengan lansia,mampu membaca dan menulis.bersedia menjadi responden.sedangkan kriteria inklusinya adalah keluarga tanpa Lansia. tidak mampu membaca dan menullis, tidak bersedia menjadi responden. Waktu pelaksanaan penelitian adalah penelitian pada bulan Agustus 2019s/d September 2019. Pengumpulan data dilakukan dengan cara pre dan post berupa pengisian kuestioner yaitu sebelum dan setelah dilakukan 
implementasi berupa pendidikan kesehatan

Metode pengumpulan data menggunakan kuesioner dengan bentuk pertanyaan menjawab benar ( B ) atau salah ( $\mathrm{S}$ ) sebanyak 10 pertanyaan berkisar tentang edukasi kesehatan. dan bentuk pertanyaan yang menjawab pilihan sangat setuju, setuju, kurang setuju dan tidak setuju untuk pengetahuan dan keterampilan keluarga dalam pencegahan risiko jatuh sebanyak 15. Data kemudian dianalisis menggunakan uji One-Sample Kolmogorov-Smirnov Test untuk medlihat normalitas data dan $u j i$ dependent $t$ test untuk melihat perbedaan2 variabel

\section{HASIL DAN PEMBAHASAN}

Hasil analisis univariat digambarkan dalam tabel di bawah ini

Tabel 1.

Analisis Karakteristi Responden di RW 09 Kelurahan Lubang Buaya

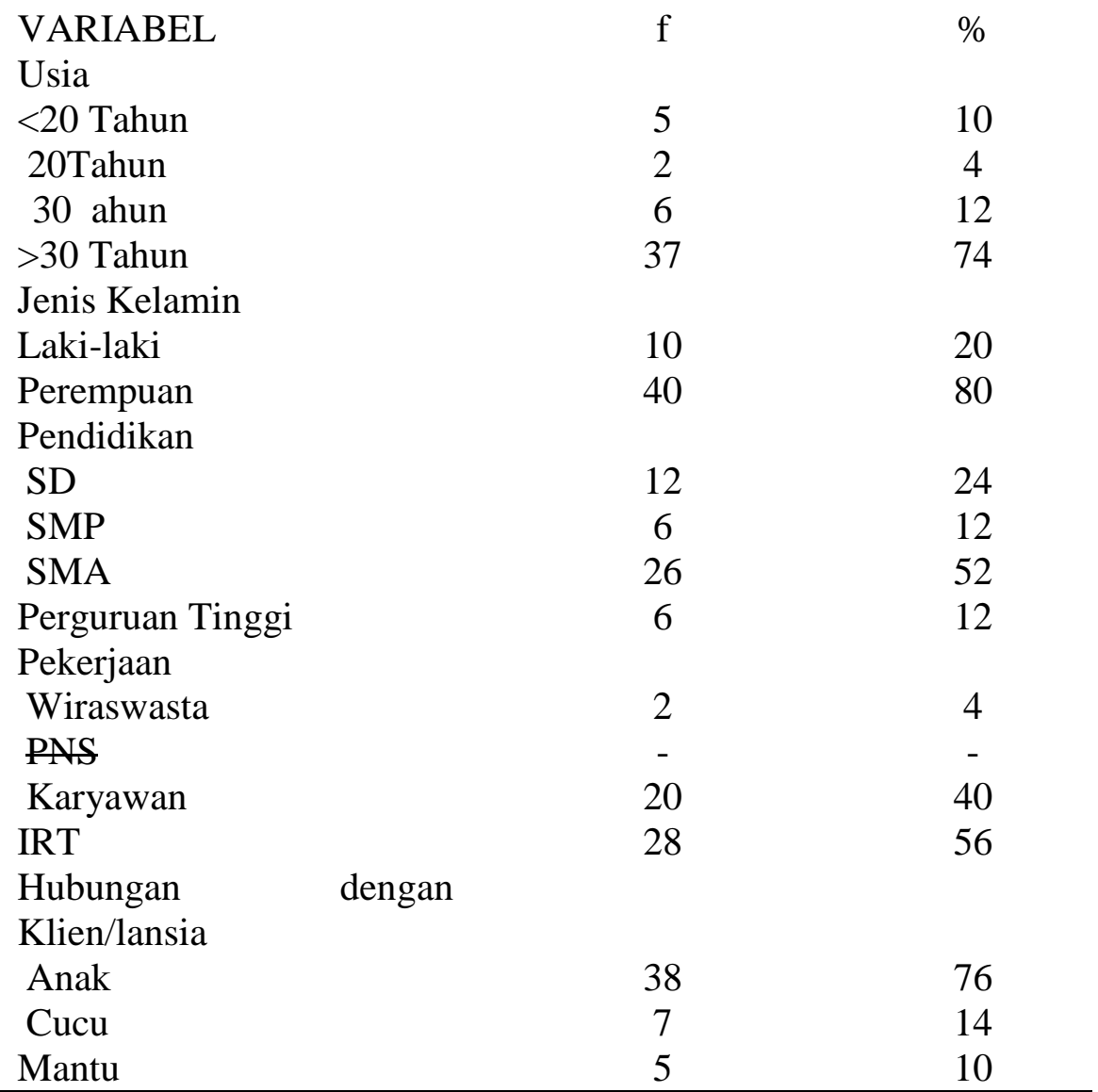


Tabel 1 menunjukkan bahwa umur tertinggi adalah berada pada usia $\geq 30$ tahun sebanyak 37 responden $74 \%)$, dengan jenis kelamin perempuan sebanyak 40 responden $(80 \%)$, berlatar belakang pendidikan SMA sebesar 26 responden $(52 \%)$ dan mempunyai

Tabel.2.

Analisis Skor Pengetahuan dan Keterampilan Sebelum dan Sesudah Edukasi

\begin{tabular}{lcccc}
\hline $\begin{array}{l}\text { Variabel } \\
\text { pengetahuan }\end{array}$ & Mean & SD & $95 \%$ CI & P value \\
$\begin{array}{l}\text { Sebelum } \\
\text { Sesudah }\end{array}$ & 7.0204 & 1.765 & $-1.425--0.411$ & $\mathbf{0 . 0 0 1}$ \\
& 7.9388 & & & \\
$\begin{array}{l}\text { Perilaku } \\
\text { Sebelum }\end{array}$ & 49.260 & 7.995 & $-3.372-1.172$ & $\mathbf{0 . 0 3 5}$ \\
Sesudah & 50.360 & & & \\
\hline
\end{tabular}

Berdasarkan tabel di atas setelah menunjukkan sebesar 49.200 dan dilakukan edukasi pada aspek setelah dilakukan edukasi ada pengetahuan ada peningkatan peningkatan sebesar 50.360 dengan dari7.0204 menjadi 7.9388 dengan selisih 1.100 . selisih 0.9183. begtitu juga aspek keterampilan sebelum edukasi

Tabel 3.

Pengaruh karakteristik responden terhadap Tk. Pengetahuan dan perilaku pencegahan jatuh

\begin{tabular}{llllll}
\hline $\begin{array}{l}\text { Variabel } \\
\text { Independent }\end{array}$ & $\begin{array}{l}\text { Variabel } \\
\text { Dependent }\end{array}$ & $\begin{array}{l}\text { Mean } \\
\text { Square }\end{array}$ & Df & F & P value \\
Jenis Kelamin & - Pengetahuan & 27.201 & 1 & 15.497 & $\mathbf{0 . 0 0 0}$ \\
& - Perilaku & 0.054 & 1 & 0.025 & $\mathbf{0 . 8 7 5}$ \\
Status Pekerjaan & - Pengetahuan & 1.145 & 2 & 0.652 & $\mathbf{0 . 5 2 8}$ \\
& & 33.678 & 2 & 8.645 & $\mathbf{0 . 0 0 1}$ \\
\hline
\end{tabular}


Berdasarkan tabel diatas hasil uji multivariat dengan mancova ditemukan bahwa jenis kelamin berpengaruh terhadap tingkat pengetahuan responden dalam pencegahan risiko jatuh dan status pekerjaan berpengaruh terhadap perilaku responden dalam pencegahan risiko jatuh

\section{PEMBAHASAN}

Hasil penelitian menunjukkan Karakteristik responden pada penelitian ini adalah sebagian besar berusiadi 30 tahun lebih sebanyak 74\%. Hasil penelitian ini sama dengan hasil penelitian Helena Winata (2013 )dalam peneliannya usia yang terbanyak adalah 33 tahun. Menurut Koesoemanto Setyonegoro, usia 30 tahun diklasifikasi dalam Usia dewasa tengah (Middle years) Usia ini mempunyai tanggumg jawab pada anggota keluarga atau orang lain salah satunya lansia. Menurut Santrock (2010 ) tugas perkembangan pada masa dewasa ini yaitu menyesuaikan diri dengan orang tua yang bertambah tua. Usia termasuk kedalam kelompok masa dewasa tengah yang disebut masa paruh baya. Menurut Notoatmodjo (2010) faktor usia berpengaruh pada aspek pengetahuan individu Semakin bertambah usia akan semakin berkembang pula daya tangkap dan pola pikirnya. .Usia berperan dalam menentukan kedewasaan seseorang, tetapi bukan satu-satunya factor yang paling menentukan karena kedewasaan ditentukan bagaimana proses pembelajaran seseorang mengubah dirinya ke arah yang selalu lebih baik, berdasarkan pengetahuan, pengalaman, atau keahliannya.

Hasilpenelitian berdasarkan jenis kelamin menunjukkan responden terbanyak adalah perempuan ( $80 \%$ ). dengan tingginya responden yang berjenis kelamin perempuan nemungkinkan untuk lebih mudah dalam mencari dan menerima informasi tentang pencegahan jatuh pada lansia, Hasil penelitian tersebut menyimpulkan bahwa nilai tradisi, sosial budaya, agama dan tanggung jawab dalam memberikan perawatan pada lansia ada pada pundak jenis kelamin perempuan baik itu anak atau menantu.hal ini karena dari segi aspek kesempatan perempuan lebih banyak waktu karena bekereja sebagai ibu rumah tangga responden mayoritas berlatar belakang pendidikan SMA (45,6\%). Penelitian ini juga sama dengan hasil penelitian Helena ( 2013 )yang menyatakan sebagian besar responden memiliki 
tingkat pendidikan yang cukup tinggi yaitu SMA. Menurutnya bahwa dengan latar belakang pendidikan SMA responden sudah memiliki ilmu dan pengetahuan yang cukup dalam hal informasi tersebut. Hal ini sejalan dengan yang dikemukakan oleh Notoatmojo ( 2012 ) factor pendidikan sangat berpengaruh. Pendidikan erat kaitannya dengan pengetahuan yang dimiliki. Menurut Notoatmojo ( 2012) bahwa Tingkat pengetahuan akan lebih mudah dipahami apabila individu semakin tinggi tingkat pendidikannya sehingga akan mempengaruhi pola pikir berusaha untuk mencari informasi tentang pencegahan jatuh pada lansia dan juga karena tingkat pendidikan yang tinggi maka responden lebih mudah dalam menerima informasi.pola sikap dan tindakan dalam meningkatkan kualitas hidup. Menurut Saragih ( 2010) Cara pandang seseorang terhadap informasi yang diterimanya tergantung dari tingkat pendidiokan yang diperoleh. Sehingga bisa dikatakan semakin tinggi tingkat pendidikannya, semakin mudah seseorang menerima informasi yang didapatnya. Sehingga apabila keluarga mendapatkan informasi tentang cara pencegahan risioko jatuh, maka keluarga dapat berfikir dan dan dapat menerapkannya pada anggota keluarganya sesuai dengan pengetahuan yang diterimanya. Pendekatan pendidikan kesehatan lebih tepat dibandingkan dengan pendelatan koersi untuk melakukan pembinaan dan peningkatan perilaku kesehatan masyarakat, karena melalui pendidikan akan terjadi penambahan pengetahuan. Hal ini dibuktikan dari hasil penelitian setelah diberikan intervensi terdapat perbedaan bermakna skor pengetahuan pencegahan jatuh pada keluarga sebelum dan sesudah tintervensi edukasi ( $\mathrm{p}=0,001)$ begitu juga aspek keterampilan Hasil analisis menunjukkan bahwa responden sebelum edukasi menunjukkan sebesar 49.200, setelah dilakukan edukasi ada peningkatan sebesar 50.360 dengan selisih 1.100. ini artinya terdapat perbedaan yang bermakna pada skor keterampilan pencegahan risiko jatuh pada keluarga sebelum dan sesudan intintervensi edukasi ( $\mathrm{p}=0.035$ ) dengan selisih rata - rata peningkatan skor perilaku $=1.100$. Menurut Kholid dan Notoatmojo tingkatan pengetahuan ini dimulai dari individi mengenal atau tahu atau mengamati sesuiatu kemudian memahami atau mampu menjelaskan tentang obyek yang diketahiuinya 
kemudian meningkat mempraktekan atau aplikasi dilanjutkan dengan analisa yaitu suatu kemampuan menjelaskan kemudian menghubungkan bagianbagian kesuatau bentuk keseluruhan atau mensintesa dan terakhir evaluasi unytuk melakukan penilaian terhadap suatu objek Notoatmojo ( 2012) Secara umum pengetahuan dan keterampilan keluarga mempunyai hubungan yang sangat erat. Hal ini disebabkan karena keterampilan yang baik dipengaruhi pengetahuan yang baik juga. Keadaan ini bisa dipengaruhi pendidikan.Hasil penelitian menunjukkan bahwa pengetahuan dan keterampilan keluarga sebelum dan sesudah dilakukan perlakuan mempunyai perbedaan yang bermakna. Artimya latar belakang pendidikan yang mayoritas SMA menjadikan keluarga memiliki pengetahuan yang lebih baik dalam mencegah risiko jatuh pada lansia. Sejalan dengan hasil penelitian Oktaviana ( 2012) bahwa keluarga di kelurahan Binjai berpengetahuan baik pada aspek pencegahan risiko jatuh pada lansia. Pengetahuan adalah suatu hasil dari rasa keingintahuan melalui proses sensoris, terutama pada mata dan telinga terhadap objek tertentu. Pengetahuan merupakan domain yang penting dalam terbentuknya perilaku terbuka atau open behavior (Donsu, 2017).

Pengetahuan atau knowledge adalah hasil penginderaan manusia atau hasil tahu seseorang terhadap suatu objekmelalui pancaindra yang dimilikinya. Panca indra manusia guna penginderaan terhadap objek yakni penglihatan, pendengaran, penciuman, rasa dan perabaan. Pada waktu penginderaan untuk menghasilkan pengetahuan tersebut dipengaruhi oleh intensitas perhatiandan persepsi terhadap objek. Pengetahuan seseorang sebagian besar diperoleh melalui indra pendengaran dan indra penglihatan (Notoatmodjo, 2014).

Hasil penelitian menghasilkan bahwa besar bidang pekerjaannya adalah ibu rumah tangga $56 \%$ yang memungkinkan lebih banyak bekerja di rumah sehingga bertanggung jawab lebih banyak berperilaku untuk mencegah kejadian jatuh pada lansiaseperti yang dikatakan oleh Dahliyani (2014) bahwa status pekerjaan berhubungan dengan aktualisasi diri seseorang dan 
mendorong seseorang lebih percaya diri dan bertanggung jawab untuk menyelesaikan tugas hal ini sesuai dengan hasil penelitian Abidemi (2005) yang menyatakan bahwa ada hubungan signifikan antara perawatan keluarga terhadap lansia dengan karakteristik sosial ekonomi keluarga. Hasil penelitian juga mememukan bahwa status pekerjaan berpengaruh terhadap perilaku responden dalam pencegahan risiko jatuh. Resiko jatuh bisa menjadi tinggi yang disebabkan karena keluarga belum sepenuhnya memberikan lingkungan yang baik bagi lansia akibat dari pekerjaan yang berimbas pada faktor social ekonomi kelurga yang tidak mendukung.. Hal tersebut sesuai dengan penelitian yang dilakukan oleh Jamebozorgi et al (2013) dengan judul "Investigation of the Prevalent FallRelated Risk Factors of Fractures in Elderly Referred to Tehran Hospitals“, yang menjelaskan bahwa salah satu penyebab lansia jatuh adalah akibat dari lingkungan yang tidak mendukung untuk lansia beraktifitas. Begitu juga hasil penelitian dari Kurniawan Afi Budi ( 2014) yang berjuduil Hubungan Pengetahuan Dan Perilaku Keluarga Dengan Resiko Jatuh Pada Lansia Di Desa Pondok Karanganom Klaten.Hasil Penelitian membuktikankan bahwa terdapat hubungan antara perilaku keluarga dengan resiko jatuh pada lansia rendah dengan faktor pendukung seperti lingkungan yang baik, socialekonomi keluarga yangbaikdan kesehatan lansia yang baik maka akan menghasilkan resiko jatuh rendah bahkan tidak beresiko.

Menurut Notoatmodjo (2007) ada tiga faktor yang mempengaruhi perilaku seseorang yaitu faktor predisposisi yaitu (sikap, pengetahuan,status sosial, usia dan jenis kelamin ), faktor pemungkin dan faktor penguiaat.. Pendapat peneliti faktor predisposisi seperti status sosial yang berhubungan dengan aspek pekerjaan berhubungan erat dengan pendapatan yang bisa memberikan kontribusi terbesar dalam melakukan pencegahan risiko jatuh pada lansia 
seperti dengan memeriksakan aspek kesehatan lansia secara teratur ke fasilitas pelayanan kesehatan.begitu juga status pekerjaan responden yang sebagiam besar ibu rumah tangga memungkinkan untuk melakukan modifikasi lingkungan dan menjaga kesehatan lansia dengan tujuan mengurangi kejadian jatuh pada lansia. Hal ini karena perempuan mempunyai pemikiran dan menyadari bahwa sebagai anakberkewajiban dalam merawat dan memberi perhatian kepada keluarga khususnya lansia seperti Hasil penelitian juga memperlihatkan bahwa sebanyak $76 \%$ responden mempunyai hubungan dengan lansia adalah sebagai anak yang melakukan perawatan pada lansia, Dibuktikan oleh Fatimah, 2010) dalam bukunya yang berjudul Merawat Manusia Lanjut Usia: Suatu Pendekatan Proses Keperawatan Gerontik menyatakan bahwa sebanyak 75\% lansia diatas 65 tahun dirawat oleh anggota keluarganya sendiri, dimana seperempatnya adalah pasangan hidup dan lebih dari sepertiga dirawat pasangan dan anak dewasa hal ini juga didukung oleh pernelitian Liu ( 2019) yang menyatakan keterlibatan keluarga dengan lansia dikarenakan adanya kewajiban dan tanggung jawab anak untuk mendampingi dan memenuhi kebutuhan mereka diperkuat juga dari hasil Penelitian Read dan Wuest dalam Pealer (2008) yang menyatakan bahwa berdasarkan nilai tradisi, sosial budaya dan agamabahwa tanggung jawab dalam memberikan perawatankepada orang tua dilakukan olehanak,ditunjang juga

Menurut Friedman (2010), yang menjadi sasaran edukasi adalah keluarga, karena keluarga bisa sebagai role model bagi anggota keluarga yang lain untuk melakukan perilaku sehat yang diharapkan. Keluarga sebagai orang yang terdekat dengan lansia perlu membekali diri dalam hal pengetahuan dan keterampilan yang bisa dsipergunakan ntuk melakukan pencegahan agar lansia tidak beresiko jatuh, , misalnya anak, cucu, menantu atau anggota keluarga yang lain. 
Pengetahuan dan perilaku yang dimiliki dengan baik, akan menciptakan lingkungan yang aman bagi lansia. Beberapa kegiatan yang bisa dilakukan oleh keluarga adalah memodifikasi lingkungan rumah seperti menjaga agar lantai tidak licin, misalnya basah atau ada genangan air.lantai terbuat dari bahan yang tidak licin dan rata, tidak ada barang-barang yang berserakan di lantai, pencahayaan yang cukup dan tidak menyilaukan serta mengurangi tangga yang ada dijalur lansia berjalan.

Hal ini sesuai dengan hasil penelitian KurniawanAfi Budi (2014). Tentang Hubungan Pengetahuan Dan Perilaku Keluarga Dengan Resiko Jatuh Pada Lansia Di Desa Pondok Karanganom Klaten yang menyatakan bahwa terdapat hubungan antara perilaku dengan resiko jatuh pada lansia., apabila perilaku yang dimiliki oleh keluarga, tidak didukung dengan salah satunya faktor pendukung seperti lingkungan yang baik, social ekonomi keluarga yang baik dan kesehatan lansia yang baik maka akan menghasilkan resiko jatuh tinggi pada lansia. Sedangkan perilaku yang baik dan didukung faktor pendukung seperti diatas maka resiko jatuh akan rendah dan bahkan tidak beresiko. Hal ini sesuai dengan hasil prosentase resiko jatuh yang beda tipis yaitu beda $3,5 \%$ untuk resiko rendah dan beda $7 \%$ untuk tidak beresiko jatuh. Sehingga risiko jatuh dapat diminimalisir dengan menggabungkan perilaku yang baik dengan faktor pendukung yang baik. Diketahui faktor resiko jatuh lansia adalah pertama, lingkungan yangburuk walaupun perilaku keluarga sudah baik akibat tidak didukungnya status social ekonomi keluarga dan kedua, kesehatan lansia / diagnosis sekunder / penyakit penyerta lansia (hipertensi)

\section{KESIMPULAN}

Kesimpulan yang dapat disimpulkan adalah

1. Karakteristik dari responden menunjukkan usia yang terbanyak adalah diatas 30 tahun, mempunyai 
jenis kelamin perempuan dan memiliki pekerjaan sebagai ibu rumah tangga serta hubungan dengan lansia adalah sebagai anak

2. Terdapat perbedaan yang signifikan pemberian edukasi terhadap pengetahuan dan keterampilan keluarga dalam pencegahan jatuh pada lansiua dibuktikan dengan terdapat perbedaanbermakna skor pengetahuan pencegahan jatuh pada lansia sebelum dan sesudah intervensi edukasi

3. Factor jenis kelamin berpengaruh terhadap tingkat pengetahuan responden dalam pencegahan risiko jatuh pada lansia sedangkan status pekerjaan berpengaruh terhadap perilaku responden dalam pencegahan risiko jatuh pada lansia.

\section{SARAN}

Berdasarkan hasil penelitian yang didapat, disarankan

1. Perlu diterapkan edukasi yang tepat pada keluarga sebagai bentuk intervensi keperawatan mandiri dalam rangka upaya pencegahan risiko jatuh

2. Keluarga perluaktif dalam mencari informasi dan melakukan pengelolaan lingkungan yang tepat untuk lansia agar terhindar dari risiko jatuh

3. Peneliti selanjutnya diharapkan dapat mengembangkan pada asppek variable dan jumlah responden sehingga ada pembanding dalam benrtuk kontrol

\section{DAFTAR PUSTAKA}

Asih. W \& Tambunan, R ( 2015 ). Pengaruh Program Pencegahan Jatuh berupa edukasi dan latihan kekuatan otot terhadap factor resiko jatuh yang dimiliki oleh lansia di Balai Perlindungan Sosial tresna Graha Werdha ( BPSTW) Ciparay Bandung. Jurnal Ilmu Kesehatan Volume 9 no 2

Astuti, A.D., Sahar, J.,\& Sukihananto. (2013). Hubungan dukungan keluarga dengan kualitas hidup lansia hipertensi di Wilayah Kerja Puskesmas Jekan Raya Kota Palangkaraya. Tesis. Depok: FIK UI.

Asiyanbola, Abidemi 2015. Patriarchy.Male Dominance. The Rple and Women empowerment in Nigeria, Paper Presented at the XXV. Internatiomal Population Conference.Tours. France

Badan Pusat Statistik. (2013). Gambaran Kesehatan Lanjut Usia Indonesia. Jakarta: Bakti Husada 
Bandiyah, S. (2009). Lanjut Usia dan Keperawatan Gerontik. Yogyakarta: Nuha Medika.

Dahliyani. (2014). Aktivitas Keluarga Dengan Tingkat Kemandirian Dalam Merawat Anggota Keluarga Dengan Penyakit DM. Jurnal Keperawatan. Vol. 11, No. 2. April 2014. Riau: Progdi Ilmu Keperawatan Universitas Riau.

Depkes RI. (2009). Sistem Kesehatan Nasional. Bentuk dan Cara Penyelenggaraan

Pembangunan Kesehatan. Jakarta.

Darmojo, B. (2011). Buku Ajar Geriatric

(IlmuKesehatanLanjutUsia). Ed 4.Jakarta:Balai Penerbit Fakultas Kedokteran Universitas Indonesia.

Dewi, S.R. (2012). Buku Ajar KeperawatanGerontik.

Yogyakarta:

https://docplayer.info/47599598

-Kuesioner-penelitian-

hubungan-peran-keluarga-

dalam-pencegahan-risiko-jatuhpada-lansia-terhadap-kejadianjatuh-di-rw-06.html diakses hari Kamis, $31 \quad$ Januari 2019.jam22;22

Donsu, J, D, T. (2017). Psikologi Keperawatan. Yogyakarta : Pustaka Baru Press. Cetakan I.

Fatimah.2010.Merawat Manusia Lanjut Usia. Jakarta : Trans Info Media.
Friedman, M., Bowden, V., Jones, E. (2010). Keperawatan Keluarga: Riset,Teori\&Praktek.Ed 5.Jakarta: EGC.

https://docplayer.info/47599598-

Kuesioner-penelitian-hubunganperan-keluarga-dalampencegahan-risiko-jatuh-padalansia-terhadap-kejadian-jatuhdi-rw-06.html diakses hari Kamis, 31 Januari jam22;22

Helena W. \& Poppy. F .( 2013 ). Pengetahun, Sikap dan Perilaku Keluarga Tentangkejadian jatuh pada Lansia. Journal Keperawatan. FIK UI

Hartini, Maryam \&Resnayati. 2015. Pengaruh Latihan Fisik Terhadap Penurunan Tekanan darah lansia hypertensi di Panti Wreda Budi Mulya Cipinang, Jakarta Timur Laporan Akhir Risbinakes.

Hutomo, K. A. ( 2015 )Hubungan Penataan Lingkungan Rumah terhadap risiko jatuh pada lansia di Desa Karangwuni Wates. Kulonprogo. Skripsi. Sekolah Tinggi Ilmu Kesehatan Aisyah. Yogjakarta.

Jamebozorgi, A. A., Kavoosi, A., Shafiee, Z., Kahlaee, A. H., \& Raei, M. (2013). Investigation of the Prevalent Fall-Related Risk Factors of Fractures in Elderly Referred to Tehran Hospitals. Medical journal of Islamic Republic of Iran, 27 (1), 23-30. 
Kamel I. M .K. Abdul Majeed,A.A.\& Ismail. S.E.S ( 2013). Risk Factor of Fall Among Elderly Living in Urban Suez. Egypt. Pan African Medical Journal 14(1)

Kementrian Kesehatan Republik Indonresia ( 2011 ). Profil Kesehatan Indonesia.tahun 2010. Jakarta. Kementerian Kesehatan Republik Indonesia.

Kurniawan, Afi Budi. (2014). Hubungan Pengetahuan dan Perilaku Keluarga Dengan Resiko Jatuh Pada Lansia di Desa Pondok Karangangon Klaten. Universitas Muhammadiyah Yogyakarta. Yogyakarta

Liu.Li Tan. ( 2009). Family Involvement in and satisfaction with long-term care facilitues in Taiwan. Taiwan Institue of Gerontology, National Cheng Kung University

Malasari,S. Jafar,N. \& Rahayu.A.I (2015). Physical Exercise toward hanging Score Of Risk Fall on Elderly. Indonesian Nursing Journal of Education and Clinic

Maryam, S. R. (2013). Pedoman Pencegahan Jatuh bagi Lansia di Rumah. Jakarta: Poltekkes Kemenkes.Maulana. 2009. Promosi Kesehatan. Jakarta. EGC

Mauk.K.L (2010 ). Gerontologi Nursing Competencies for Care ( $2^{\text {nd }}$ ed ). Sudbury.Janes and Ballet Publisher
Maryam,Mia.Hartini. 2008. Mengenal Usia Lanjut dan Perawatannya. Jakarta. Salemba Medika

Mubarak, dkk. 2007. Promosi Kesehatan . sebuah pengantar proses belajar mengajar dalam pendidikan. Yogyakarta.Graha Ilmu.

Nies, M.A., \& McEwen, M. 2007. Community/ Public Health Nursing: Promoting the Health of Populations. St. Louis, Missouri: Saunders Elsevier.

Notoatmodjo, Soekidjo. (2003). Pendidikan dan Perilaku Kesehatan. Jakarta : PT. Rineka Cipta.

Notoatmodjo, S. (2010). Metodologi penelitian kesehatan. Jakarta: PT Rineka Cipta
Notoatmodjo.S ( 2012 )/ Promosi Kesehatan dan Perilaku Kesehatan. Jakarta:

PT Rineka Cipta Nugroho, W ( 2008 ). Keperawatan gerontik \& deriatrik. Jakarta, EGC

Nursalam ( 2016). Metodelogi Penelitian Ilmu Keperawatan. Jakarta . Salaemba Medika

OktavianaSry. Pengetahuan Dan Sikap Keluarga Tentang Pencegahan Kejadian Jatuh Pada Lansia Di Kelurahan Pahlawan Binjai. Jurnal Keperawatan Holilistik. Vol1 no 3.2012 
Pealer.M ( 2008 ) Sibling relatiomship and Family Dynamic Effect on The Careof a sick elderly Parent ( $s$ ).California State University Long Beach ProQuest Disertation and Thesis

Potter, Patricia A. \& Anne.G.Perry ( 2009 ). Fundamrntal of Nursing. Jakarta. Salemba Medika

Santrock, J.W. 2010. Remaja (Edisi Kesebelas). Jakarta: Erlangga

Saragih, F,.S. 2010. Pengaruh Penyuluhan Terhadap Pengetahuan dan Sikap Ibu Tentang Makanan Sehat dan Gizi Seimbang di Desa Merek Raya Kecamatan Raya Kabupaten Simalungun Tahun 2010. Skripsi. Universitas Sumatera Utara ( USU )

Setyabudi SR., (2016). Hubungan dukungan keluarga dengan risiko jatuh dirumah di Notoyudan RW 24 Pringgokusuman Yogyakarta.

Naskah Publikasi Suhana Haeriyanto, Ni Luh Putu Ekarini, Dewi Lusiani. Stigma Remaja Terhadap ODHA Studi terhadap pelajar SMA di wilayah Jakarta Timur, JKEP, 2019
Susilo. W. Limyat, Y \% Decky,G, (2017). The Risk Of Fallling in Elderly increased with age growth and unaffected by gender. Journal of Medicine and Health 3

Utami, Nita dan Suratni,Suratini ( 2017). Hubungan Dukungan Keluarga Dengan Risiko Jatuh Pada Lansia di Desa Kraksakan Lumbun grejo Tempel Sleman.Yogyakarta, Universitas Aisyiyah 